\title{
The UK Research Assessment Exercise and Its Enlightenment
}

\author{
Yan Wang \\ Guangdong University of Science \& Technology, Dongguan, China
}

\begin{abstract}
Keywords: REF, Evaluation System, the United Kingdom
\end{abstract}
\begin{abstract}
Research assessment is an important tool and mean of scientific research management, and it is also the compass of scientific research in colleges and universities. British has engaged in scientific research evaluation for 30 years, and during this process, it has formed a set of effective and complete scientific research evaluation mechanism with a certain representative function. On the basis of "Research Assessment Exercise" (RAE), in 2006, UK began brewing "Research Excellence Framework" (REF), and it was formally implemented in 2014, completed in 2015. By introducing the organization structure, evaluation experts, evaluation content and standard, evaluation method of the evaluation system of scientific research in UK, this paper puts forward some suggestions on the evaluation of scientific research in China.
\end{abstract}

\section{Introduction}

Colleges and universities are the main body of knowledge innovation, and it is the main force to promote social development and progress.Therefore, as an important part of the national scientific research system, the evaluation and identification of the scientific research system has been paid more attention by all walks of life. Scientific research evaluation is an important means and tools of modern science and technology management, and its importance has become increasingly prominent. Throughout the scientific evaluation system all over the world, from the beginning of 1986, the United Kingdom began to implement the scientific research evaluation mechanism in all universities across the country, and after 30 years of adjustment and reform, it has formed a set of more advanced, parallel effective research evaluation mechanism, which has played the role of learning and reference for the research evaluation system that is still not perfect scientific in our country.

\section{Overview of REF evaluation system}

The evaluation activities of scientific research in British universities are organized and carried out by four organizations - England Higher Education Fund Committee, Scotland Higher Education Fund Committee, Welsh Higher Education Fund Committee and Northern Ireland employment and Study Department. The purpose of the evaluation is to ensure the quality of scientific research in British universities, classify scientific research level in colleges and universities, and provide scientific research funding basis for government departments and funding agencies. From the beginning of 1986, the United Kingdom implemented the scientific research assessment mechanism in the country, and about once every 3-5 years, all the university's scientific research assessment activities. In 2008, after the sixth evaluation, RAE gradually revealed itself. Thus, the British higher education foundation decided to establish a new evaluation system - Research Excellence Framework (REF). On the basis of the essence of RAE, REF has carried out a comprehensive reform.

Organization. REF assessment is still carried out by the joint organization and implementation of the above 4 institutions of higher education, and the specific work is: the England Higher Education Funding Council REF team on behalf of the above 4 funded institutions to carry out specialized management, and supervision by the REF group to carry out its supervision, and the REF supervisory team members are composed of representatives of the above 4 funded institutions[1].

Assessment unit. According to the connotation of the subject and the new requirements of the 
society for the development of scientific research, REF assessment system was classified according to the category of the University. Different disciplines form different evaluation units and different assessment units are specifically evaluated by the respective Expert Committee[2]. In the REF evaluation, there are a total of 36 assessment units (UoA), taking into account the differences between the different UoA, REF first classify the UoA according to the nature and characteristics, forming four universities, namely the A group, the B group, the $C$ group and the $D$ group. All the UoA in the four university groups continue to use a set of evaluation methods, including evaluation experts, evaluation methods and evaluation criteria[3].A group has 6 evaluation units, including clinical medicine, biological science and agriculture, etc.; B group has 9 evaluation units, including physics, chemistry, electronics, engineering, materials and computers, etc.; $\mathrm{C}$ group has 11 evaluation units, including architecture, archaeology, law, education, economics, sociology and so on; D group has 10 evaluation units, mainly including linguistics, history, philosophy, art and so on.

The composition and responsibilities of the experts. According to the four university division, REF first set up a large group of 4 main experts (15-25 members), as well as the basis of the 36 assessment units (UoA), 36 sub experts (10-30 members). In addition, taking into account the depth and breadth of expertise in the assessment, the REF assessment also set up a panel of candidates for review and the alternate assessment experts mainly participate in the evaluation of outcomes and impact. The main responsibility of the main group of experts is to make the assessment standards and implementation details together with the group of experts, to ensure the consistency of standards among the group of sub experts. The main responsibilities of the deputy group of experts are to carry out assessment work according to the audit criteria of this group and to provide preliminary results of the assessment to the main group of experts.

Content of assessment REF. The main contents of the assessment are output of scientific research achievement, influence of scientific research, research environment. The output of scientific research achievement is the core element of REF evaluation, and the evaluation weight is $65 \%$. REF assessments focus on quality rather than quantity, requiring each participating personnel can not submit no more than 4 best research achievements, which is not limited to academic papers, it can be other outcomes, such as monographs, textbooks, art exhibitions, audio-visual products and so on. Influence of scientific research assessment weight is $20 \%$. The scope of the study's influence includes economic, social, cultural, quality of life, public policy and health, environment, service, and so on. These influences are those that have brought about the benefits of economic, social, cultural, quality of life, and public policy[4]. Scientific research environment assessment weight is $15 \%$, mainly including the evaluation of scientific research investment, scientific research management, scientific research potential and so on.

Evaluation method. In order to reduce the workload of experts, at the same time to ensure the greatest degree of experts to make a reliable assessment for the quality of academic papers[5]. The main work is the evaluation of the citation rate of papers, but REF also recognizes the limitations of the paper's citation rate, they will also refer to the expert's subjective assessment. For the influence of research results in the field of academic research, REF use case description and influence template approach. Participating units fill in the influence template, taking case and quantitative data and indicators as evidence for experts to assess the use of decision making. For the evaluation of scientific research environment, it needs to fill in environmental templates according to the participating units[6].

Evaluation results. Deputy group of experts makes a preliminary examination for the materials submitted by colleges and Universities from three aspects of scientific research achievement, research influence and scientific research environment. On the basis of the results of deputy expert group, the major group of experts evaluate it again according to the prospect of scientific research results and other indicators, at last forming the final assessment results. REF final assessment of the results on the University and research personnel are divided into five grades. REF assessment results include master expert group report and rating, number of participating researchers and outcomes, minutes of the meeting of master expert group and associate expert group, and the evaluation results can be related to the information on the Internet, reflecting the fairness and 
transparency of the evaluation process.

\section{The Enlightenment and Suggestion of REF on the Evaluation System of Scientific Research in Universities and Colleges in China}

To improve the scientific research level of colleges and universities based on the quality of scientific research. The current evaluation system of scientific research in our country is mainly the quantity index. Taking the added a bachelor's degree conferring unit evaluation index system in Guangdong province as a example, if the number of papers published per year is not less than 0.5, it was rated 5 points; If it is not less than 0.4 , it was rated 4 points. It can be seen that it obviously has too much attention to the paper and topic number in China. Therefore, China should learn from the practice of British REF, on the evaluation mechanism of scientific research in colleges and universities, it Should fully implement the spirit of the core of scientific research quality,correctly handle the relationship between the quantity of scientific research and the quality of scientific research, highlight the status of peer review, change the past form.

Paying attention to the importance of social benefits of scientific research, promoting the development of university industry. At present, China does not pay enough attention to the social benefit and academic influence of the scientific research evaluation. But according to the UK's REF regulations, the academic influence weights $20 \%$ of the total score. The way of scientific research achievement is mainly provided by the researcher, which shows the contribution of the research to the society, economy, culture, health, environment and quality of life. Of course, Chinese government and academia have also gradually realized this problem, the government promulgated a series of documents, put forward "To promote the industrialization of scientific and technological achievements", "Higher education should firmly establish the awareness of the initiative for the social services, all-round development of services, promote the combination of research and production, accelerate the transformation of scientific and technological achievements". But we started late, and it still need to study carefully and learn from the British research evaluation mechanism, to form a scientific research evaluation system in line with China's national conditions.

Establishing a systematic, continuous, open and transparent evaluation system. First, to avoid administrative intervention, the UK's REF is implemented by 4 higher education funding agencies, non-governmental organizations. Second, in the selection of the assessment experts, it, is also to be fair, as far as possible to balance he expert review of the age, qualifications, institutions, gender and so on. Third, the assessment of experts from a wide range of sources, the experts and scholars are from various universities in the UK, and there are experts from the UK's large enterprises, government officials and some non-governmental experts and scholars and so on. Fourth, before the implementation of the assessment work, REF assessment standards and methods are developed and published by each discipline expert group according to the characteristics of the subject of this group, at the same time, the determination of evaluation unit, the formation of expert group, the evaluation procedures and evaluation results, each link of the information can be obtained from the Internet Higher Education Foundation[7]. Fifth, the UK's scientific research evaluation mechanism promotes that the British universities get more funding through the evaluation, instead of direct funding from government departments through administrative means. In addition, for all the scientific research personnel in Colleges and universities, it is also a spur and encouragement. Even some teacher pass the assessment of the professor, they also need to participate in the assessment, which virtually can bring some pressure to the colleges and universities teacher, requiring them to continue to improve themselves.

\section{Reference}

[1] Liu Ya. British scientific research evaluation system of higher education system reform and evaluation [J]. the latest progress and Countermeasures of science and technology, 2013,8.

[2] Du Debin, Zhang Renkai, Li Pengfei. REF evaluation system of British universities and Its 
Enlightenment [J]. Chinese University Science and technology, 2014,3.

[3] Lu Xiaozhong. Comparative education [M]. Beijing: People's education press, 2005

[4] Tian Feng. Research Excellence Framework of the British scientific research [J]. development and evaluation of higher education, 2012, (6):18.

[5] Song Liping. REF and the trend of scientific research evaluation[J]. library and information work, 2011,55 (22): 60-100.

[6] Xu Fang, Liu Wenbin, Li Xiaoxuan. REF research influence evaluation method and Its Revelation [J]. science and technology management, 2014,7.

[7] Cheng Jingwen. Research on the reform of scientific research evaluation in contemporary British Universities[D]. Chengdu: Sichuan Normal University, 2014.

Author introduction: Wang Yan (1983-), female, master, assistant researcher, research direction: university scientific research management. 